\title{
EFEKTIFITAS GAMIFICATION BERBASIS BLENDED LEARNING PADA MATA KULIAH PENDIDIKAN EKONOMI
}

\author{
Saiful Anwar, Universitas Pamulang \\ dosen00902@unpam.ac.id \\ Novi Marlena, Universitas Negeri Surabaya \\ novimarlena@unesa.ac.id \\ Retno Wulandari, Universitas Negeri Malang \\ retno.wulandari.ft@um.ac.id
}

\begin{abstract}
ABSTRAK
Tujuan penelitian adalah melihat efektifitas konsep gamification yang diterapkan dalam proses pembelajaran mata kuliah Pembaharuan Pembelajaran Pendidikan Ekonomi. Pendekatan yang digunakan dalam penelitian ini adalah pendekatan kualitatif. Subjek dalam penelitian ini adalah mahasiswa kelas 06PIEE001 FKIP Universitas Pamulang. Dalam penelitian ini mengadopsi konsep Marczewski's Gamification Framework yang terdiri dari 8 pertanyaan yaitu 1) what is being gamified; 2) why is it being gamified; 3) who are the users; 4) how is it being gamified; 5) analytics are set up; 6) tested with users; 7) acted on feedback; and 8) released the solution. Berdasarkan hasil analisis data dan pembahasan, dapat disimpulkan yaitu 1) proses pembelajaran pada matakuliah Pembaharuan Pembelajaran Pendidikan Ekonomi dapat dilakukan dengan konsep gamification dengan menggabungkan pembelajaran tatap muka di kelas dengan pembelajaran online learning; 2) respon mahasiswa dalam proses pembelajaran dengan konsep gamification sebagian besar tertarik karena merupakan hal baru bagi mereka; 3) terdapat nurturant effect selama selama konsep gamification diterapkan di kelas.

Kata Kunci: Gamification, Pendidikan Ekonomi, E-learning.
\end{abstract}

\begin{abstract}
The purpose of the study is to see the effectiveness of the concept of gamification that is applied in the learning process of the subject of Renewal of Economic Education Learning. The approach used in this study is a qualitative approach. Subjects in this study are students of class 06PIEE001 FKIP Pamulang University. In this study adopted Marczewski's Gamification Framework concept which consists of 8 questions: 1) what is being gamified; 2) why is it being gamified; 3) who are the users; 4) how is it being gamified; 5) analytics are set up; 6) tested with users; 7) acted on feedback; and 8) released the solution. Based on the results of data analysis and discussion, it can be concluded that 1) the learning process in the course of Renewal of Economic Education Learning can be done with the concept of gamification by combining faceto-face learning in the classroom with online learning learning; 2) student response in learning process with gamification concept mostly interested
\end{abstract}


because it is new for them; 3) there is a nurturant effect for as long as the concept of gamification is applied in the class.

Keywords: Gamification, Economics Education, E-learning.

\section{PENDAHULUAN}

Sebagai seorang tenaga pendidik pada sebuah institusi pendidikan harus paham dan sadar bahwa dalam kegiatan proses belajar mengajar menjadi lebih bermakna apabila kegiatan belajar mengajar tersebut sesuai dengan kondisi yang terjadi di sekeliling mahasiswa berdasarkan pengamatan yang telah dilakukan peneliti dapat diambil kesimpulan bahwa mendidik mahasiswa di era sekarang ini memiliki tantangan tersendiri jika dibandingkan dengan mendidik mahasiswa satu dekade sebelumnya, mendidik mahasiswa sekarang ini yang notabene nya adalah generasi digital harus ekstra kreatif dan inovatif terutama terkait dengan penggunaan teknologi dalam proses belajar mengajar di kelas.

Salah satu trik yang dapat dilakukan seorang pendidik agar proses belajar dikelas tidak hanya sekedar menghafal adalah dengan menyesuaikan proses pembelajaran sesuai dengan apa disukai oleh mahasiswanya di kelas. Kelas 06PIEE001 salah satu contohnya, kelas ini adalah salah satu kelas yang memiliki keunikan tersendiri, setiap jam istirahat maupun sore hari ketika proses pembelajaran di kelas telah selesai, peneliti selalu menjumpai sebagian besar mahasiswa yang tercatat sebagai anggota kelas tersebut masih duduk bergerombol di kelas maupun diluar kelas dengan memegang alat komunikasi masing-masing, ketika dilakukan observasi lebih lanjut ternyata diperoleh hasil yang cukup mengejutkan karena sebagian besar dari mereka sedang melakukan battle game antar mahasiswa. Hal tersebut membuat peneliti tertarik ingin menerapkan konsep gamification di dalam proses pembelajaran pada kelas 06PIEE001.

Gamification is an integration of game elements and game thinking in activities that are not games (Kiryakova, 2014). Gamification juga diartikan oleh Zichermann \& Cunningham (Romdhoni \& Wibowo, 2014) sebagai proses penggunaan teknik desain game dan mekanisme game pada konteks non-game untuk mengikat pengguna untuk mencapai suatu tujuan. Sedangkan Jusuf, Heni (2016) menjabarkan gamification sebagai pendekatan pembelajaran menggunakan elemen-elemen di dalam game atau video game dengan tujuan memotivasi para mahasiswa dalam proses pembelajaran dan memaksimalkan perasaan enjoy dan engagement terhadap proses pembelajaran tersebut.

Berdasarkan uraian di atas dapat diambil kesimpulan bahwa gamification bukanlah sebuah pendekatan pembelajaran dimana seluruh kelas bermain video game secara bersama-sama dikelas melainkan sekedar mengadaptasi aturanaturan dan konsep game di dalam kelas dengan tujuan agar proses pembelajaran di kelas menjadi nyaman dan bermakna. Secara sederhana konsep gamification dapat diterapkan di dunia pendidikan dengan mengikuti 5 langkah sederhana (Huang \& Soman, 2013) yaitu: (1) understanding the target \& audience and the content; (2) defining learning objectives; (3) structuring the experience; (4) indentifyng resouces and (5) applying gamification element.

Dalam penelitian ini konsep gamification dibuat lebih sederhana menyesuaikan dengan karakteristik mahasiswa dan tujuan pembelajaran, 
konsep gamification di dalam penelitian ini menggabungkan konsep pembelajaran di dalam kelas dan sistem e-learning berbasis moodle. Konsep gamification disesuaikan pula dengan Matakuliah Pembaharuan Pembelajaran Pendidikan Ekonomi yang menuntut siswa berfikir kreatif dan inovatif dalam menuangkan ide-idenya sebagai calon guru ekonomi. Proses penyusunan konsep gamification secara garis besar sudah dibuat oleh peneliti tetapi ditawarkan dan disesuaikan dengan permintaan mahasiswa karena peneliti berkeinginan agar proses penerapan konsep gamification berjalan nyaman tetapi bermakna.

Penelitian ini mengadopsi konsep gamification yang disebut Marczewski's Gamification Framework yang terdiri dari 8 pertanyaan yaitu 1) what is being gamified; 2) why is it being gamified; 3) who are the users; 4) how is it being gamified; 5) analytics are set up; 6) tested with users; 7) acted on feedback; and 8) released the solution. Tujuan penelitian ini adalah untuk melihat efektifitas konsep gamification yang diterapkan dalam proses pembelajaran pada mata kuliah Pembaharuan Pembelajaran Pendidikan Ekonomi.

\section{METODE PENELITIAN}

Penelitian ini menggunakan penelitian kualitatif dengan menggunakan pendekatan eksperimental dimana peneliti dengan sengaja membangkitkan timbulnya suatu kejadian atau keadaan. Subjek dalam penelitian ini adalah mahasiswa kelas 06PIEE001 FKIP Universitas Pamulang yang mengikuti matakuliah Pembaharuan Pembelajaran Pendidikan Ekonomi. Rancangan dalam penelitian ini terdiri dari 4 tahap (Anwar, 2016) yaitu: (1) merencanakan tindakan meliputi: menyusun skenario pembelajaran baik skenario pembelajaran tatap muka di kelas maupun pembelajaran secara online; (2) mengumpulkan data, meliputi: pengamatan kegiatan pembelajaran dan pelaksanaan wawancara bersama dengan mitra observasi, mitra observasi dalam penelitian ini adalah rekan sejaat dosen yang mengampu matakuliah pembaharuan pada kelas yang berbeda; (3) menganalisis data; (4) membuat laporan hasil penelitian. Prosedur pengumpulan data yang digunakan dalam penelitian ini meliputi pengisian lembar observasi yang digunakan untuk melihat seluruh aktivitas belajar mengajar di kelas, catatan lapangan yang diperuntukkan terutama ketika melihat dan memonitor pembelajaran secara online, dan wawancara.

Analisis data dalam penelitian ini terdiri dari tiga tahap yaitu: (1) mereduksi data, yaitu suatu kegiatan penyeleksian, pemfokusan, dan penyederhanaan data yang dimulai sejak pengumpulan data sampai penyusunan laporan penelitian. Data yang dimaksud meliputi transkrip pelaksanaan pembelajaran, rekaman wawancara, hasil observasi maupun catatan lapangan. Kegiatan penyederhanaan data yang telah terkumpul dimaksudkan untuk mendapatkan informasi yang jelas dan bermakna sehingga dapat dipertanggungjawabkan; (2) penyajian data dilakukan dengan cara menyusun secara naratif informasi-informasi yang telah diperoleh dari hasil reduksi sehingga dapat memberikan penarikan kesimpulan dan pengambilan tindakan. Data yang telah disajikan selanjutnya dibuat penafsiran dan evaluasi 
yaitu dapat berupa penyelesaian tentang: (a) perbedaan antara rancangan dan pelaksanaan tindakan; (b) perlunya perubahan tindakan; (c) alternatif tindakan yang dianggap tepat; (d) persepsi peneliti, teman sejawat dan dosen yang terlibat dalam pengamatan dan perencanaan lapangan terhadap tindakan yang telah dilakukan; (e) hambatan yang dihadapi dan mengapa hambatan itu muncul dan sebagainya; (3) penarikan kesimpulan adalah memberikan kesimpulan terhadap hasil penafsiran dan evaluasi. Kegiatan ini mencakup makna data serta memberi penjelasan. Verifikasi merupakan proses memvalidasi data yang disimpulkan. Kegiatan verifikasi yaitu menguji kebenaran, kekokohan, dan kecocokan makna-makna yang muncul dari kegiatan dan dapat dikatakan sebagai pengambilan intisari dari sajian data yang telah terorganisasi dalam bentuk pernyataan atau kalimat yang singkat, padat, dan bermakna (Anwar, 2016).

\section{HASIL PENELITIAN DAN PEMBAHASAN}

Berdasarkan observasi awal yang dilakukan oleh peneliti, mahasiswa pada kelas 06PIEE001 cenderung sudah melek teknologi hal ini terbukti dari perilaku yang dilakukan mahasiswa setiap harinya ketika di kampus, sebagian besar dari anggota kelas adalah seorang gamer baik games yang dimainkan melalui aplikasi android maupun games yang dibawa setiap harinya semisal ludo maupun uno stako. Sedangkan jika ditelisik lebih lanjut tentang perilaku anggota kelas ketika pembelajaran e-learning selama 4 semester ke belakang dapat ditarik kesimpulan bahwa semua anggota kelas sangat aktif di dalam forum diskusi e-learning terbukti ketika pekan-pekan e-learning selama 3 semester ini aktivitas kelas tidak pernah kurang dari 8000 aktivitas per pekan $e$ learning.

Setelah melakukan observasi awal, peneliti menyusun konsep gamification dengan modifikasi sesuai karakteristik kelas tetapi tanpa mengurangi tahapan konsep gamification. Framework gamification pada matakuliah pembaharuan pembelajaran pendidikan ekonomi peneliti rangkum pada tabel di bawah ini.

Tabel 1. Framework Gamification Matakuliah Pembaharuan Pembelajaran Pendidikan Ekonomi

\begin{tabular}{lll}
\hline No & Tahapan & Keterangan \\
\hline 1 & Perencanaan & \multicolumn{2}{c}{} \\
\hline & What is being & Pada tahapan ini peneliti menjabarkan gamification ke dalam \\
& gamified & sistem blended learning, yaitu menggabungkan sistem online \\
& & $(40 \%)$ dan offline (60\%). Sistem online learning \\
& menggunakan aplikasi e-learning UNPAM yang didalamnya \\
& mencakup folder materi, forum bertempur (forum berdiskusi), \\
& assigment tugas , kuis daya serap, dan angket kepuasan \\
& mahasiswa untuk mengetahui kemampuan dosen dalam \\
& memberikan layanan pembelajaran yang memotivasi, \\
& mendorong keterlibatan, kontekstual, dan problem solving. \\
\hline & Mata kuliah pembaharuan pendidikan ekonomi seringkali \\
& Gamified & terkesan susah, rumit dan melelahkan bagi sebagian besar \\
& mahasiswa karena mereka harus mengerahkan segenap ide
\end{tabular}




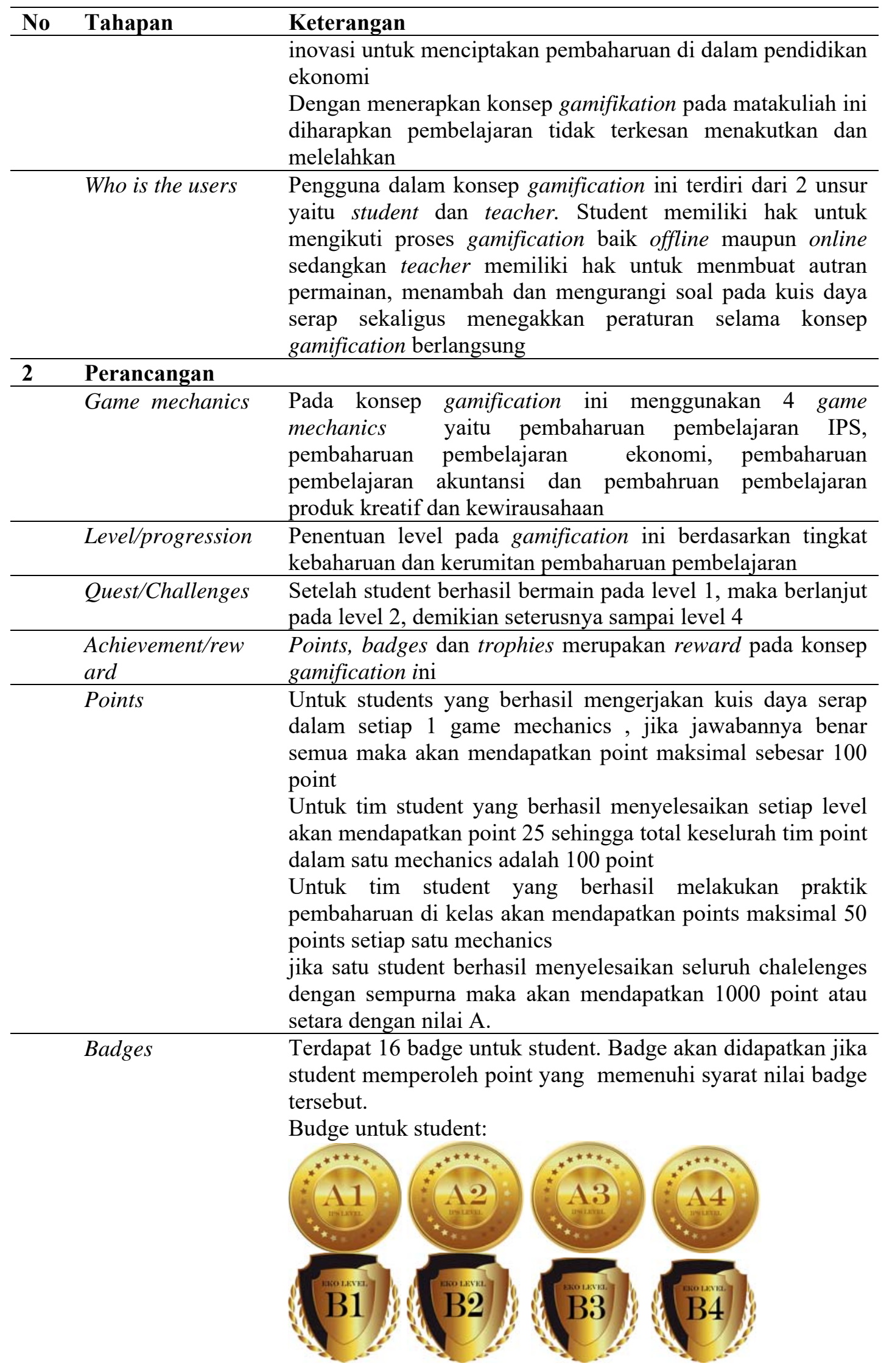




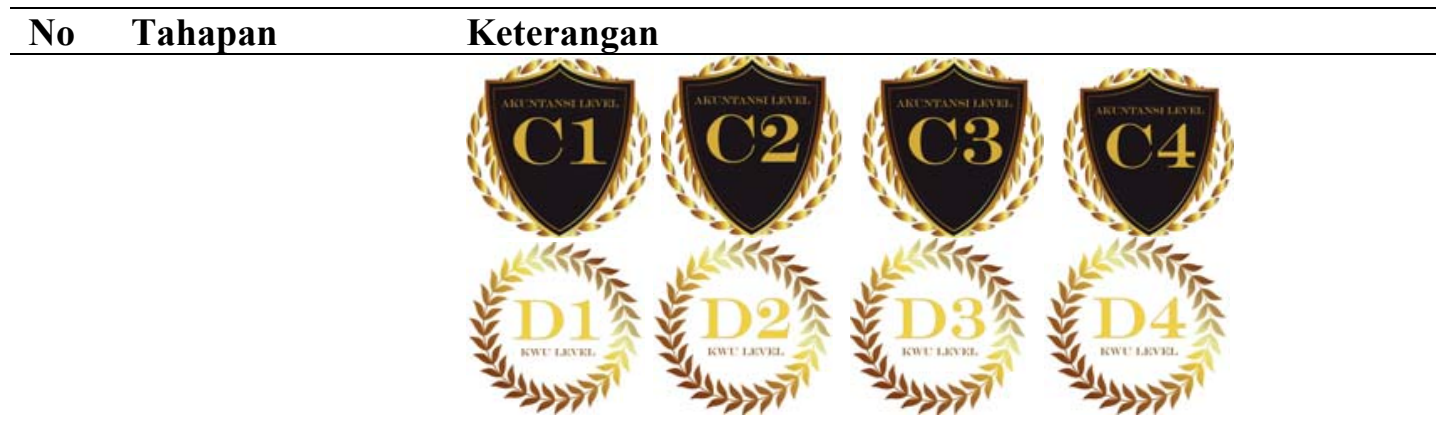

Tropies

Terdapat 4 trophies untuk student. Jika pemain memperoleh point yang menuhi kriteria syarat nilai trophie tersebut. 4 trophies untuk student:

Sumber: diadopsi dari Andrzej M. (2013)
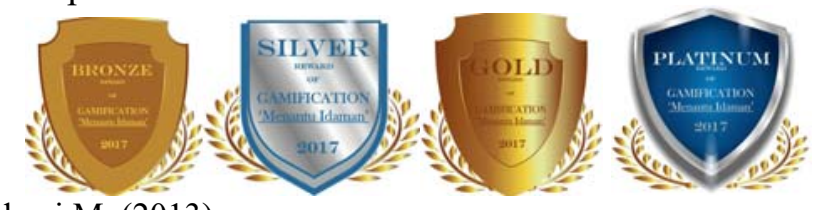

Sedangkan game rules dan game play terjabarkan dalam gambar di bawah ini:
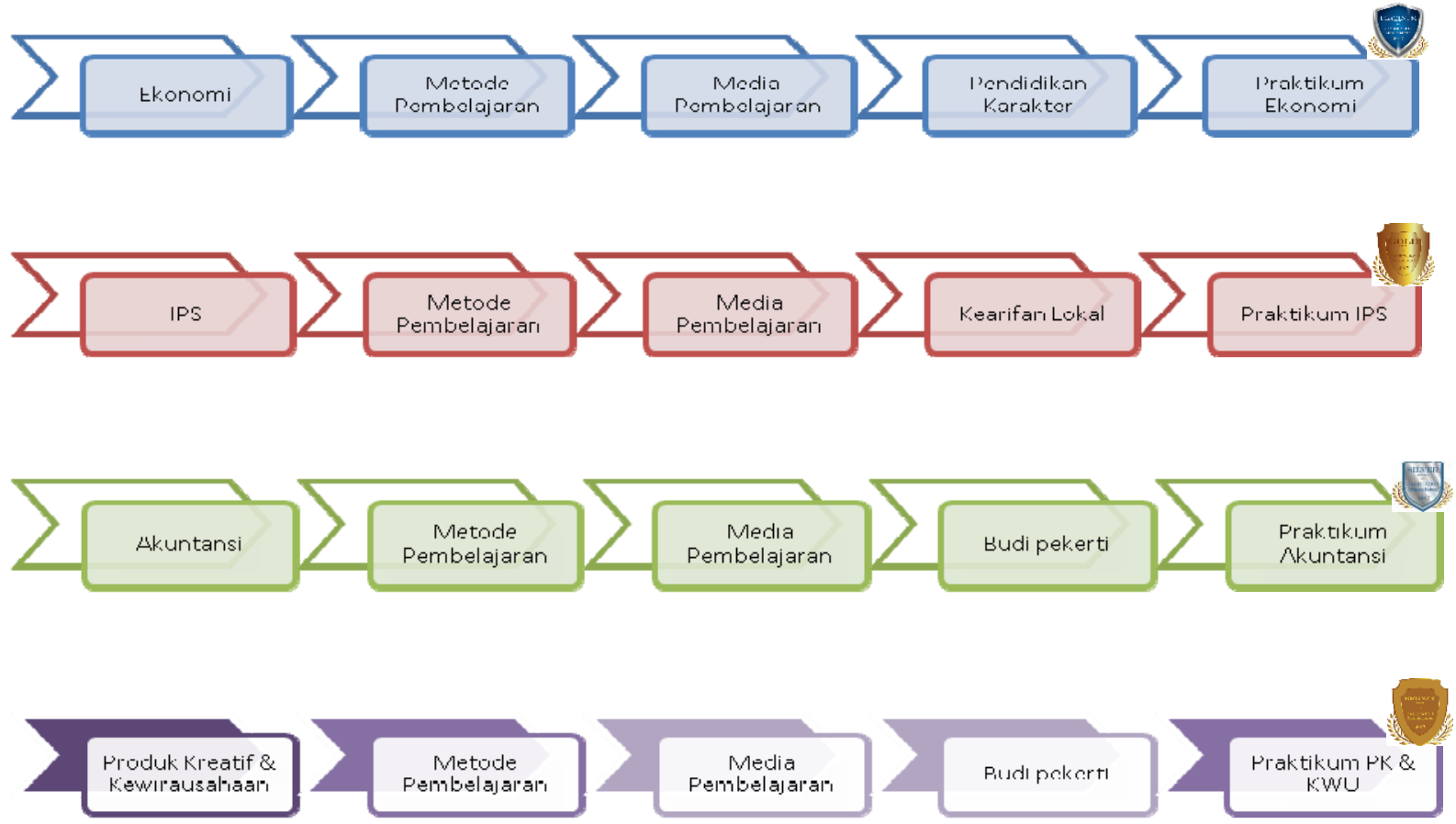

\section{Gambar 1. Games Rules dan Trophie pada mahasiswa}

Dalam tataran pelaksanaan games rules yang tergambar di atas diterapkan secara fleksibel, sehingga setiap kelompok boleh memulai permainan berdasarkan mata kuliah mana yang paling disukai maupun yang paling dianggap mudah dalam penerapan inovasinya, tetapi fleksibilitas tersebut juga di batasi aturan-aturan yang telah disepakati bersama yaitu jika satu kelompok sudah memilih satu game mechanics mereka harus 
menyelesaikan satu game mechanics dengan tutas dan tidak bisa melanjutkan ke games mechanics pilihan kedua dan seterusnya sampai empat games mechanics tuntas pelaksanaannya.

Setelah menetapkan games rules, peneliti merancang game play yang harus ditaati oleh seluruh peserta games. Gambar alur 1 games pada gamification penelitian ini sudah menggabungkan pembelajaran secara online dan tatap muka dikelas. Sehingga secara umum pembelajran online dalam konsep gamification ini merupakan bagian inti dan tidak terpisahkan dengan proses gamification secara tatap muka di kelas. Secara sederhana alur games yang harus dilakukan mahasiswa dapat dirangkum dalam bentuk bagan alur di Gambar 2.

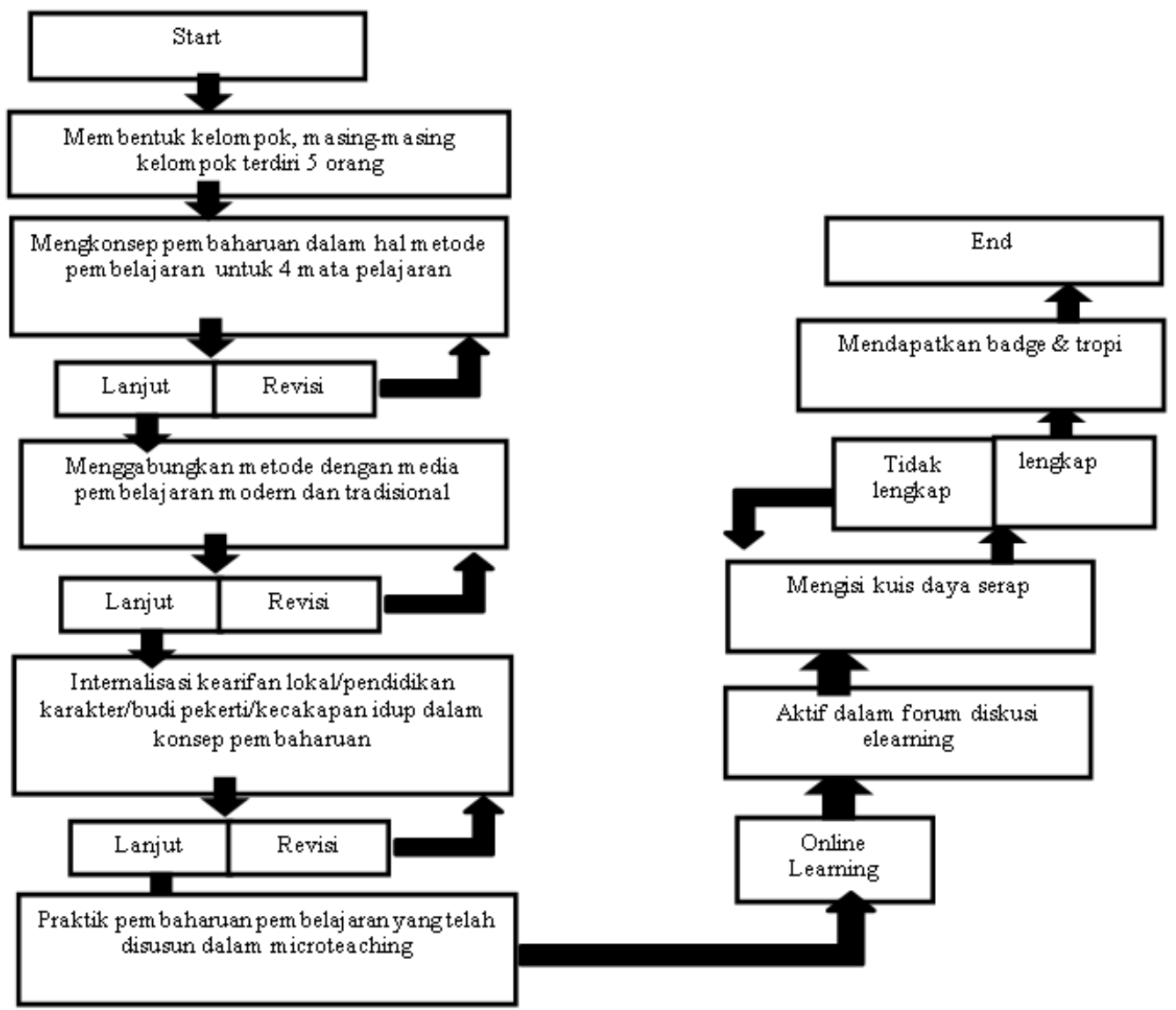

Gambar 2. Bagan Alur Game Play pada student

Setelah melakukan proses perencanaan dan perancangan gamification maka tahapan selanjutnya adalah tahapan implementasi di kelas. Pada tahap pelaksanaan konsep gamification di kelas secara umum berjalan lancar tetapi ada beberapa penyesuaian terutama dalam hal penyebutan nama di kelas, karena peneliti juga menggunakan media sosial berupa facebook sebagai penunjang performa gamification selain web e-learning Universitas Pamulang maka untuk menyamarkan nama mahasiswa maka seluruh student menggunakan tokoh-tokoh di bidang pendidikan sebagai nama di dalam gamification. Sedangkan pada pelaksaan di kelas peneliti tetap konsisten menggunakan nama samaran sehingga mahasiswa harus membuat kartu 
pengenal dan menyebut rekan mahasiswa diskusinya dengan nama samaran yang telah dibuat sebelumnya. Sebetulnya jika dilihat dari sisi seorang dosen penggunaan nama samaran membuat dosen bekerja lebih keras lagi dan berat karena harus menghafal nama-nama samaran satu persatu, sedangkan jika dilihat dari sudut pandang siswa ternyata terdapat nurturant effect yang tidak terduga sebelumnya, dengan pola komunikasi menggunakan nama yang baru membuat mahasiswa seperti mengenal teman-teman yang baru, pola komunikasi yang semula terkesan acuh-tak acuh karena sibuk dengan gadgetnya masing-masing kini lebih terkesan mencair tanpa mengubah kepribadian masing-masing mahasiswa.

Penggunaan e-learning dalam proses gamification bukan dimaksudkan sebagai pengganti tatap muka di kelas melainkan integrate dengan pembelajaran di kelas, hal ini dilakukan untuk meningkatkan efektifitas proses pembelajaran dengan konsep gamification, hal ini selaras dengan penelitian (Kiyakova, 2014) yang menyatakan bahawa e-learning is suitbable for easy and effective integration of gamification. Meskipun demikian terdapat beberapa kendala di dalam pelaksanaan gamification pada pembelajaran $e$ learning antara lain terkadang proses adu pendapat antar kelompok dalam forum diskusi e-learning terkadang ada beberapa jawaban yang tidak sinkron karena terkendala sinyal seluler sehingga ada beberapa mahasiswa terkesan ketinggalan menanggapi adu argumen pada forum adu pendapat. Selain itu dalam kuis daya serap menggunakan pola tes online sehingga ketika selesai menjawab satu soal maka secara otomatis mahasiswa tersebut tidak bisa membaca soal yang telah dijawab, hal ini dikeluhkan oleh mahasiswa ditengahtengah proses gamification apalagi peneliti membatasi waktu membaca setiap soal hanya 2 menit.

Secara garis besar aktivitas mahasiswa dalam pembelajaran terlihat aktif meskipun tidak semua mahasiswa mendapatkan nilai maksimal. Selama proses gamification minat dan rasa ingin tahu mahasiswa semakin meningkat sehingga kemampuan social skills, communication skills, dan analytical terasah. Khusus untuk social skills dan communication skills peneliti hanya membatasasi diri hanya meninjau 10 keterampilan sosial dan komunikasi yaitu working together, tolerance, decision making, aggreing, disaggreing appropriately, responsibility, building on others idea, active listening, honesty, coming to consensus. Sebagai contoh selama proses gamification kemampuan mahasiswa dalam melakukan proses komunikasi semakin terasah hal ini dapat dilihat ketika satu mahasiswa mengemukakan ketidaksetujuannya terhadap pendapat seseorang, mahasiswa tersebut sekarang lebih mengkritik ide dan tidak mengkritik personal mahasiswa yang mengemukakan ide awal.

Tabel 2. Hasil akhir penilaian akhir dari gamification

\begin{tabular}{clclll}
\hline No & Skor & Jumlah Mahasiswa & \% & Nilai & Trophi \\
\hline 1 & Diatas 900 & 5 & 20 & A & Platimum \\
\hline 2 & 800 s.d 899 & 7 & 28 & A- & Gold \\
\hline 3 & 700 s.d 799 & 11 & 44 & B & Silver \\
\hline 4 & 600 s.d 699 & 1 & 4 & C & Bronze \\
\hline 5 & Dibawah 600 & 1 & 4 & D & - \\
\hline & Total & $\mathbf{2 5}$ & $\mathbf{1 0 0}$ & & \\
\hline
\end{tabular}


Selain terkait dengan keterampilan sosial dan keterampilan berkomunikasi. Efektifitas konsep gamification secara umum dapat dilihat dari hasil akhir penilaian akhir di kelas seperti tabel 2.

Selain keaktifan mahasiswa yang selalu terjaga setiap pertemuannya terdapat pula nurturant effect selama konsep selama konsep gamification diterapkan di kelas antara lain pola komunikasi antar siswa lebih terjalin kembali, mahasiswa lebih melek terhadap teknologi dan persepsi mahasiswa terhadap kemampuan pedagogik dan profesional dosen semakin meningkat

Selama proses penerapan gamification tidak selalu berjalan lancar terdapat beberapa kendala yang dialami antara lain a) keterbatasan di dalam menggunggah video yang telah dibuat mahasiwa di dalam konten e-learning Universitas Pamulang sehingga peneliti menggunakan bantuan media sosial berupa facebook maupun youtube sebagai media pembelajaran jika harus mengunggah video berdurasi panjang; b) karena ada sebagian content yang diunggah via media sosial sedangkan rasa percaya diri sebagian mahasiswa cenderung rendah terutama mahasiswa yang berasal dari daerah atau kota kecil maka selama proses pembelajaran seluruh mahasiswa menggunakan nama samaran dan hal ini cukup menyita waktu dalam proses penyesuaiannya; c) kelompok-kelompok mahasiswa sangat bagus di dalam mengkonsep dan membuat media pembelajaran penunjang konsep gamification tetapi ketika digunakan praktik seringkali media pembelajaran yang telah dibuat tidak dipergunakan secara maksimal.

\section{SIMPULAN}

Berdasarkan hasil analisis data dan pembahasan, dapat disimpulkan beberapa hal sebagai berikut: 1) proses pembelajaran pada matakuliah Pembaharuan Pembelajaran Pendidikan Ekonomi dengan konsep gamification berbasis Blended Learning berjalan efektif hal terlihat dari 25 mahasiswa hanya 2 mahasiswa yang tidak mencapai nilai $\mathrm{B}$; 2) respon mahasiswa dalam proses pembelajaran dengan konsep gamification sebagian besar tertarik karena merupakan hal baru bagi mereka; 3) terdapat nurturant effect selama konsep selama konsep gamification diterapkan di kelas antara lain pola komunikasi antar siswa lebih tejalin kembali, mahasiswa lebih melek terhadap teknologi dan persepsi mahasiswa terhadap kemampuan pedagogik dan profesional dosen semakin meningkat; 4) terdapat beberapa hambatan yang ditemui dalam penelitian ini antara lain: a) keterbatasan di dalam menggunggah video yang telah dibuat mahasiwa di dalam konten e-learning Universitas Pamulang sehingga peneliti menggunakan bantuan media sosial berupa facebook maupun youtube sebagai media pembelajaran jika harus mengunggah video berdurasi panjang ; b) karena ada sebagian content yang diunggah via media sosial sedangkan rasa percaya diri sebagian mahasiswa cenderung rendah terutama mahasiswa yang berasal dari daerah atau kota kecil maka selama proses pembelajaran seluruh mahasiswa menggunakan nama samaran dan hal ini cukup menyita waktu dalam proses penyesuaiannya. 


\section{DAFTAR RUJUKAN}

Andrzej M. 2013. A Simple Gamification Framework. https://marczewski.me.uk/gamification-framework/, diakses 21 April 2017

Anwar, Saiful. 2016. The Use Of Carousel Feedback In Order To Improve Student Personal Relationships Taking Part A Village Vocational Programme Concerned With Starfruit Farming In Depok (A District Of West Java). Jurnal Eduka Vol 2 No. 2. http://openjournal.unpam.ac.id/index.php/Eduka/article/view/207

Bunchball. 2010. Gamification 101: An Introduction To The Use of Game Dynamics To Influence Behavior. http://www.bunchball.com/sites/defaults/files/download/gamification101. pdf, diakses 4 April 2017

Dicheva, Darina \& Dichev, Christo \& Agre, Gennody \& Angelova, Galia. 2015. Gamification In Education: A Systematic Mapping Study. Journal Educational Technology \& Society 18(3) Halaman 75-88.

Hsin-Huang, Wendy \& Soman, Dilip. 2013. A Practitioner's Guide To Gamification Of Education. Toronto: Rotman School Of Management.

Jusuf, Heni. 2016. Penggunaan Gamifikasi Dalam Proses Pembelajaran. Jurnal TICOM Vol. 5 No. 1 September 2016.

Kiryakova, Gabriela \& Angelova, Nadezhda \& Yordanova, Lina. 2014. Gamification In Education. Bulgaria: Faculty of Economics Trakia University

Romdhoni, Fachri, Hilmi \& Wibowo, Radityo Prasetianto. 2014. Penerapan Gamification Pada Aplikasi Interaktif Pembelajaran SQL Berbasis Web. Jurnal TEKNIK POMITS Vol. 1 No 1 tahun 2014.

Sandusky, Susan. 2017. Gamification in Education. The University Of Aizona

Sari, Bety, Wulan \& Utami, Ema \& Al Fatta Hanif. 2015. Penerapan Konsep Gamification Pada Pembelajaran tenses Bahasa Inggris Berbasis Web. Jurnal Ilmiah SISFOTENIKA Vol. 5 No. 2 Juli 2015.

Zichermann, G \& Cunningham C. 2011. Gamification By Design: Implementing Game Mechanics in web and Mobile Apps, Sebastopol O'Reilly Media. 